Rev. Int. Contam. Ambie. 33 (Especial Biotecnología e ingeniería ambiental) 23-32, 2017

DOI: 10.20937/RICA.2017.33.esp01.02

\title{
PORE WATER CONTRIBUTION TO IN-SITU SAMPLING OF POLYCYCLIC AROMATIC HYDROCARBONS IN SEDIMENT USING LOW DENSITY POLYETHYLENE
}

\author{
Damien A. DEVAULT ${ }^{1,2 *}$ and Catherine GOURLAY-FRANCÉ 3
}

${ }^{1}$ Laboratoire Matériaux et Molécules en Milieu Agressifs, UA - UMR ECOFOG, DSI, Campus, Universitaire de Schoelcher. 97275 Schoelcher, Martinique, France

${ }^{2}$ Faculté de Pharmacie, Université Paris Sud. UMR 8079, CNRS, AgroParisTech, Université Paris-Saclay, France

${ }^{3}$ Unité Hydrosystèmes et Bioprocédés, Centre d'Antony. 1 rue Pierre-Gilles de Gennes, CS 10030, 92761 Antony Cedex, France

* Corresponding author: damien.devault@martinique.univ-ag.fr

(Received July 2015; accepted October 2016)

Key words: LDPE, PAH, dissolved contaminant, adsorption, representativeness, urban area

\begin{abstract}
Passive sampling with low-density polyethylene (LDPE) was assessed to study the way it accumulates contaminants in sediment. Strips of LDPE were deployed in river sediment for a period of two months to evaluate their polycyclic aromatic hydrocarbon (PAH) accumulation following two modes: LDPE buried in sediment and exposed to pore water flow and contaminants desorbed from particles were compared to LDPE strips in the same sediment but in a confined space. The results present an obvious difference of accumulation between the two modes of exposure. LDPE exposed to pore water accumulated PAH depending on their hydrophobicity whereas LDPE only exposed to contaminant desorption from confined particles did not accumulate nor desorb PAH significantly. This observation shows that LDPE only takes up PAH present in pore water and not the PAH bound to sediment particles. Accumulation in LDPE is not the result of forced desorption from particles. The present study also found that LDPE sampling cannot estimate adsorbed molecules in confined sediment nor in turbid water. LDPE is an efficient tool for investigating pore water, the fate of micropollutants in sediment, the effect of bioturbation and bioirrigation on micropollutants and the effect of micropollutants on bioturbation activity.
\end{abstract}

Palabras clave: PBD, HAP, contaminante disuelto, adsorción, representatividad, área urbana

\section{RESUMEN}

Se llevó a cabo un muestreo pasivo con polietileno de baja densidad (PBD) para analizar la manera en que puede acumular contaminantes en el sedimento. Se emplearon tiras de PBD en sedimento de río por un periodo de dos meses para evaluar la acumulación de hidrocarburos aromáticos policíclicos (HAP) a través de dos modalidades: PBD enterrado en el sedimento y expuesto al flujo de agua intersticial y PBD expuesto a contaminantes desadsorbidos de partículas en el mismo sedimento pero en espacios confinados. Los resultados muestran una diferencia en la acumulación entre 
ambas modalidades de exposición. El PBD expuesto al agua intersticial acumuló HAP dependiendo de su hidrofobicidad, mientras que el PBD expuesto solamente a la desadsorción de partículas confinadas no acumuló o desadsorbió HAP de manera significativa. Esto muestra que el PBD sólo toma HAP presentes en el agua intersticial y no aquellos unidos a partículas en el sedimento. La acumulación de HAP en el PBD confinado, no es el resultado de la desadsorción forzada de las partículas. El presente estudio encontró que el muestreo con PBD no puede estimar las moléculas adsorbidas en sedimento confinado o en agua turbia. El PBD es una herramienta eficiente para investigar el agua intersticial, el destino de microcontaminantes en sedimentos, el efecto de la bioturbidez y la bioirrigación en microcontaminantes, así como el efecto de éstos en la actividad de bioturbación.

\section{INTRODUCTION}

Watershed and marine contamination leads to pollutant accumulation in sediment. From sediment, pollutants can alter the ecosystem performance through: (i) chronic exposure via desorption into the water column or roots (Ek et al. 2004), and (ii) flood events with sediment movement and dispersion triggering sudden desorption of large quantities of pollutants (Guimont 2005). Suitable means of estimating sediment contamination is a major concern and its complexity is exacerbated by adsorption diversity (Ehlers et al. 2006). Sediment extraction does not provide information about the potential to contaminate the biota through desorption (Robertson et al. 1994).

Indeed, water sampling is required for environmental monitoring as defined by the Water Framework Directive, even though it is only a weakly representative method (Coynel et al. 2004, Allan et al. 2005, Ghestem et al. 2008, Hering et al. 2010). Expensive water sampling campaigns can only provide normalizable but unsuitable data. The other matrices, (e.g. sediment and biota) are regarded as alternatives to water sampling. While water and biota surveys provide information about chemical contamination (i.e. bioavailable chemical fluxes), sediment analysis provides information about contamination risks because of the large quantities of chemicals it sequesters. But sediment (including related suspended matter) and biota have their own interpretative limits as well, like metabolization, migration and chemical selectivity. Integrating chemical concentration peaks in filtered water can be achieved with passive samplers, as described below. Passive sampling has, for a decade, been considered as an alternative to environmental matrix sampling -but what does it actually sample?

Passive samplers have become widely used since the early 1990's to collect organic contaminants in aquatic environments (Petty et al. 2000). They exploit the affinity of organic contaminants for polymers, which is estimated by the partition coefficient $\left(\mathrm{K}_{\mathrm{D}}\right)$ between the environmental matrix and the sampling material. The performance of each device differs depending on the adsorbent material used and the configuration of the setup, with different sampling rates (Rs) for each device. These passive samplers are increasingly being used (Esteve-Turrillas et al. 2008) and have become the main means of aquatic environment monitoring. Their use is now progressively extending to solid matrices but one pivotal question is: Can we use the chemicals accumulated to represent all the chemicals present in the sampled environment?. Several authors (e.g. Allan et al. 2009) consider that passive samplers could provide an estimation of the bioavailable contaminants present in fluid matrices. Few studies allow interpreting the sampling in solid matrices owing to the key role of organic matter, especially in sediment (Cornelissen et al. 2008, Sormunen et al. 2008 and 2010). Allan et al. (2012) investigated the freely dissolved polycyclic aromatic hydrocarbon (PAH) content of water by incubating low-density polyethylene (LDPE) strips in sediment. They used PAH, as in the present study, because of their apolar characteristics. In the same way, Charrasse et al. (2014) investigated sediment pore water partition in agitated sediment monitored by LDPE.

Focusing on adsorption/desorption processes, adsorption is defined as the rapid and reversible accumulation of molecules at solid-liquid interfaces (Weber et al. 1991). The solid-liquid distribution is quantified using the partition coefficient $\mathrm{K}_{\mathrm{D}}$ between solid surface and water. Theoretically, the accumulation of contaminants in the passive sampler leads to the depletion of contaminants in the water boundary layer close to the sampler, which may force some contaminant desorption from particles or other ligands. Hence, the passive sampler may accumulate readily available plus originally bound contaminants. Passive sampling does not produce information about 
the origin of the contaminant sampled (i.e. molecules present in the pore water or molecules desorbed from a particle association). Briefly, the solid-liquid distribution and transport of organic chemicals (in the present article, $\mathrm{PAH}$ ) depend on the organic matter of natural sediment and dissolved organic matter in solution. Ignorance of such recruitment could generate incorrect estimation of the sediment contamination.

The present study was designed to investigate passive sampling in sediment.

Among passive samplers, the semi-permeable membrane device (SPMD) (Huckins et al. 1990) is largely applied in routine aquatic organic contamination surveys. The SPMD is formed by a non-porous LDPE bag containing triolein. Booij et al. (1998) indicated that LDPE significantly contributed to the accumulation. Hence, LDPE strips could also be used as a passive sampler of organic contaminants. By calculation, Booij et al. (1998) demonstrated that LDPE mainly accumulates truly dissolved hydrophobic organic contaminants from pore water. However, environmental managers remain sceptical: they are not convinced by such arguments, especially when they manage turbid water (e.g. estuaries) or large amounts of sediment (e.g. reservoirs, dams). Do passive samplers only sample truly dissolved organic chemicals? Do passive sampling processes favor desorption from solid particles, as the case for metals (Harper et al. 1998, 1999 and 2000)? The present experiment intends to study passive sampling, using LDPE in a sediment matrix in order to determine the route of accumulation of pollutants in passive samplers from solid contaminated matrix. In a reductio ad absurdum approach, passive samplers were deployed: (i) buried in sediment, exposed to pore water and contaminated sediment particles, or (ii) enclosed in a test tube, only exposed to sediment particles eliminating pore water flux - and related contaminants.

LDPE strips were deployed in situ, as passive samplers (Rantalainen et al. 1998, Booij et al. 2003, Hawthorne et al. 2008, Fernandez et al. 2009) to limit bias from matrix disruption (Jonker et al. 2001). Since LDPE is increasingly employed, especially for abrasive matrices such as sediment (Booij et al. 2003), it was chosen for use in this study.

The objective of the study was to determine the mode of recruitment of accumulated organic molecules in passive samplers regarding exposure type, time and $\mathrm{K}_{\mathrm{OW}}$ (the partition coefficient between octanol and water, illustrating the hydrophobicity). Desorbing profile observed concomitantly with spiked deuterated molecules provide information on the reverse kinetics.

\section{MATERIALS AND METHODS}

\section{Chemicals}

Suprasolve acetone, methanol and hexane provided by Merck KGaA (Darmstadt, Germany) and picograde $n$-heptane from the LGC company (Teddington, UK) were used in the experiments. Glassware was washed and combusted $\left(500{ }^{\circ} \mathrm{C}\right.$ for $\left.4 \mathrm{~h}\right)$. Samples were stored in the dark at a temperature of $-18^{\circ} \mathrm{C}$ and they were as soon as possible.

External calibrations, performed with the PAH standard Mix31 as performance reference compounds (PRCs) (acenaphthylene- $d_{8}$, fluorene- $d_{10}$, anthracene- $d_{10}$, fluorene- $d_{10}$, and benzo(g,h,i) perylene- $d_{12}$ ) and internal calibration compounds (naphthalene- $d_{8}$, acenaphthene- $d_{10}$, phenanthrene$d_{10}$, chrysene- $d_{12}$ and perylene- $d_{12}$ ) were provided by Cluzeau Info Labo (Sainte-Foy la-Grande, France) and produced by Dr. Ehrenstorfer $\mathrm{GmbH}$ (Augsburg, Germany). LDPE was provided by Manutan (Gonesse, France).

\section{LDPE preperation and extraction}

LDPE strips were cleaned and spiked with PRCs following the protocol detailed in Lorgeoux (2008). Briefly, LDPE strips $(1 \times 10 \mathrm{~cm})$ were immerged successively in hydrophobic (ethylacetate/heptane, $50 / 50, \mathrm{v} / \mathrm{v}, 20 \mathrm{~mL} /$ strip) and ultra high quality (UHQ) water on a rotary table $(130 \mathrm{rpm})$. The hydrophobic bath lasted $24 \mathrm{~h}$ (renewed once) and the hydrophilic bath $96 \mathrm{~h}$ (renewed once). The LDPE strips were spiked with PRCs (acenaphthylene- $d_{8}$, fluorene$d_{10}$, anthracene- $d_{10}$, fluorene- $d_{10}$, and benzo(g,h,i) perylene- $\left.d_{12}\right)$ in methanol/water $(50 / 50, \mathrm{v} / \mathrm{v})$ for $24 \mathrm{~h}$.

\section{Deployment modes}

LDPE were deployed in the sediment of Rungis stream, which flows near Orly airport before flowing along the $2 \times 6$ - lane motorway controlling the southern access to Paris. LDPE strips $(10 \times 1 \mathrm{~cm})$ were exposed to sediment following two modes: (i) directly by burying them $3 \mathrm{~cm}$ below the sediment surface or (ii) inserted into glass test tubes to limit pore water circulation and to force the recruitment from close sediment (Fig. 1). Test tube mouths were $3 \mathrm{~cm}$ deep.

To limit sediment upheaval when the LDPE was retrieved, the LDPE strips buried in situ were attached to a nylon thread. Three strips of each deployment mode were retrieved regularly over $36 \mathrm{~d}$ (17 times). Thirty $\mathrm{mL}$ of sediment was retrieved one week before the experiment, then one week after. 


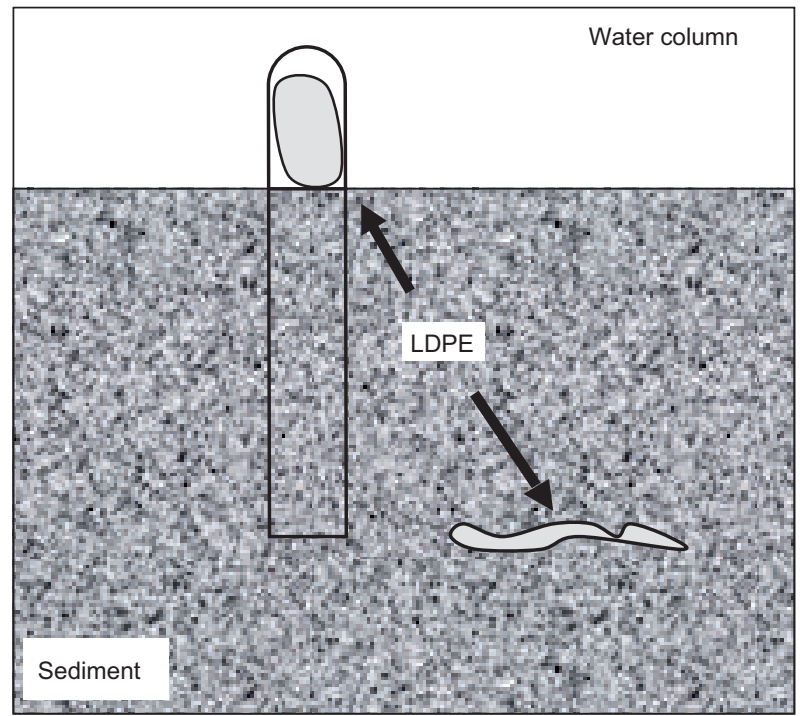

FIg. 1. Passive sampling deployment modes. Left: buried LOW Density PolyEthylene strips. Right: test tube Low Density PolyEthylene strips (ldpe)

\section{Analytical methods}

After exposure, LDPE were succinctly waterwashed and wiped to remove all the sediment particles. Then, the clean strips were bathed in the hydrophobic mix (ethylacetate/heptane, 50/50, v/v, $20 \mathrm{~mL} / \mathrm{strip}$ ) for $48 \mathrm{~h}$. Sediment was lyophilized and sieved with a $2 \mathrm{~mm}$ mesh sieve and then homogenized, later on $0.5 \mathrm{~g}$ was taken for micro-wave assisted extraction (Mars II from the CEM corporation (Matthews, NC, USA)). Hexane/ acetone $(50 / 50, \mathrm{v} / \mathrm{v}, 2 \mathrm{~mL} / \mathrm{sample})$ extraction consisted of a $1600 \mathrm{~W}$ microwave applied to samples heated from ambient to $80^{\circ} \mathrm{C}$ following a $15 \mathrm{~min}$ ramp, then a 10 min plateau. Extracts were purified on a Florisil column.
The PAH (16 substances from the USEPA list) and PRCs were quantified using a TraceGC ultrachromatograph coupled with a TraceDSQ mass spectrometer (GC-MS) from Thermofinnigan (Waltham, MA, USA). Briefly, the splitless mode (injector temperature: 280 ${ }^{\circ} \mathrm{C}$ ) was set up at an initial temperature of $45^{\circ} \mathrm{C}$. The first step had a temperature increase rate of $35^{\circ} \mathrm{C} / \mathrm{min}$ up to $180^{\circ} \mathrm{C}$, then a second step at $8^{\circ} \mathrm{C} / \mathrm{min}$ up to $280^{\circ} \mathrm{C}$ and, finally, a $10 \mathrm{~min}$ plateau at $280^{\circ} \mathrm{C}$. The specific ion mode detection conditions were: temperature $=300^{\circ} \mathrm{C}$; detector voltage $(E M V)=2600 \mathrm{~V}$.

\section{Internal calibration and data confidence}

Naphthalene was discarded from the analysis because of its low recovery. Although high variability was observed in some triplicates (maximum relative standard deviation, $103 \%$ ), the overall reproducibility remained acceptable: $75 \%$ of the relative standard deviations in PAH concentration triplicates were less than $38 \%$. Bathing steps increased reproducibility performance, in situ contamination and mineralization variability (Harper et al. 1998). Internal calibration allowed each result to be weighted with the corresponding reproducibility performance.

Quantification limits on sediment were about 2 to $4 \mathrm{ng} / \mathrm{g}$ and about 25 to $50 \mathrm{ng} / \mathrm{g}$ in LDPE for three to four ring $\mathrm{PAH}$ and five to six ring $\mathrm{PAH}$, respectively.

\section{RESULTS}

\section{Sediment contamination}

The PAH sediment concentrations measured each week (Fig. 2) were almost constant over the two

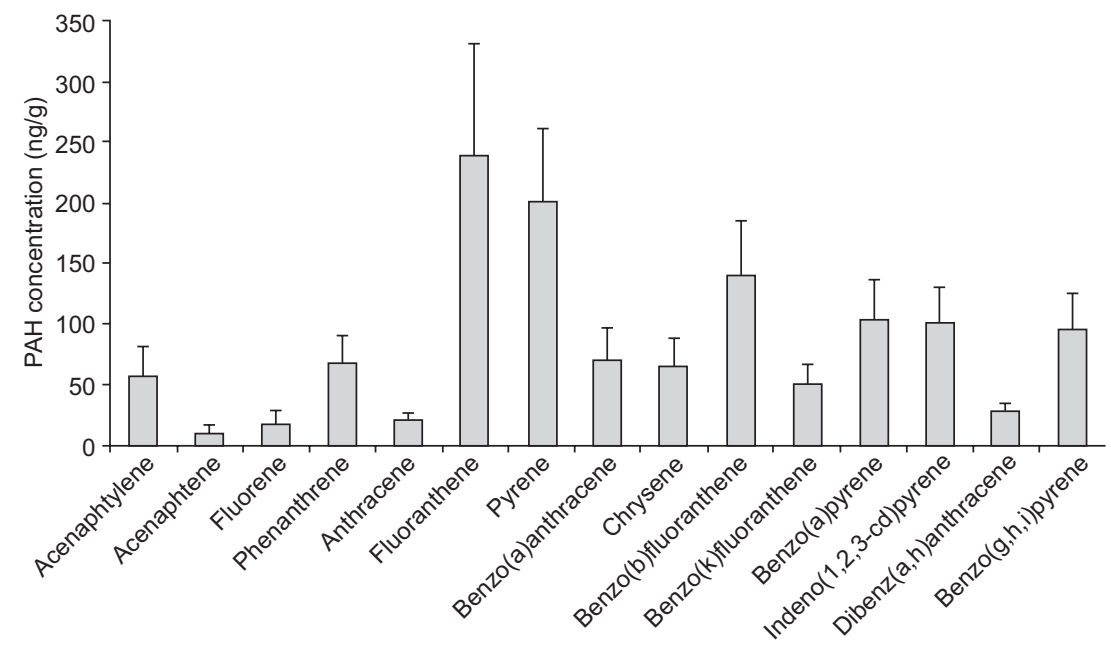

Fig. 2. Polycycic aromatic hydrocarbons (PAH) average concentrations in sediment over time (weekly sampling during 60 days). Data from the United States Environmental Protection Agency. 
months. Rungis stream sediment was as contaminated in the same way as RTC-CRM141 sediment provided by LGC Promochem (Augsburg, Germany). Although this sediment is more contaminated than samples from unpolluted areas, the Rungis stream sediment is less contaminated than at hotspots like relevant harbours such as New York (NIST-1944). Moreover, Rungis stream sediment presented the whole range of PAH, including all the 16 USEPA PAH, which is characteristic of urban sediments (Van Metre et al. 2000).

\section{Accumulation of PAH in buried LDPE strips}

Whatever the molecules, the greatest deviation (excess) from the accumulation trend was observed after about 5 to 10 days for fluoranthene and pyrene. A similar initially increasing profile was observed for each PAH (Fig. 3b), except dibenzo[a,h]anthracene, followed by a desorption event (Fig. 3a).

Accumulation of PAH in LDPE (Fig. 3) segregates $\mathrm{PAH}$ into three categories depending on $\mathrm{PAH}$ $\mathrm{LogK}_{\mathrm{OW}}$ or aromaticity:
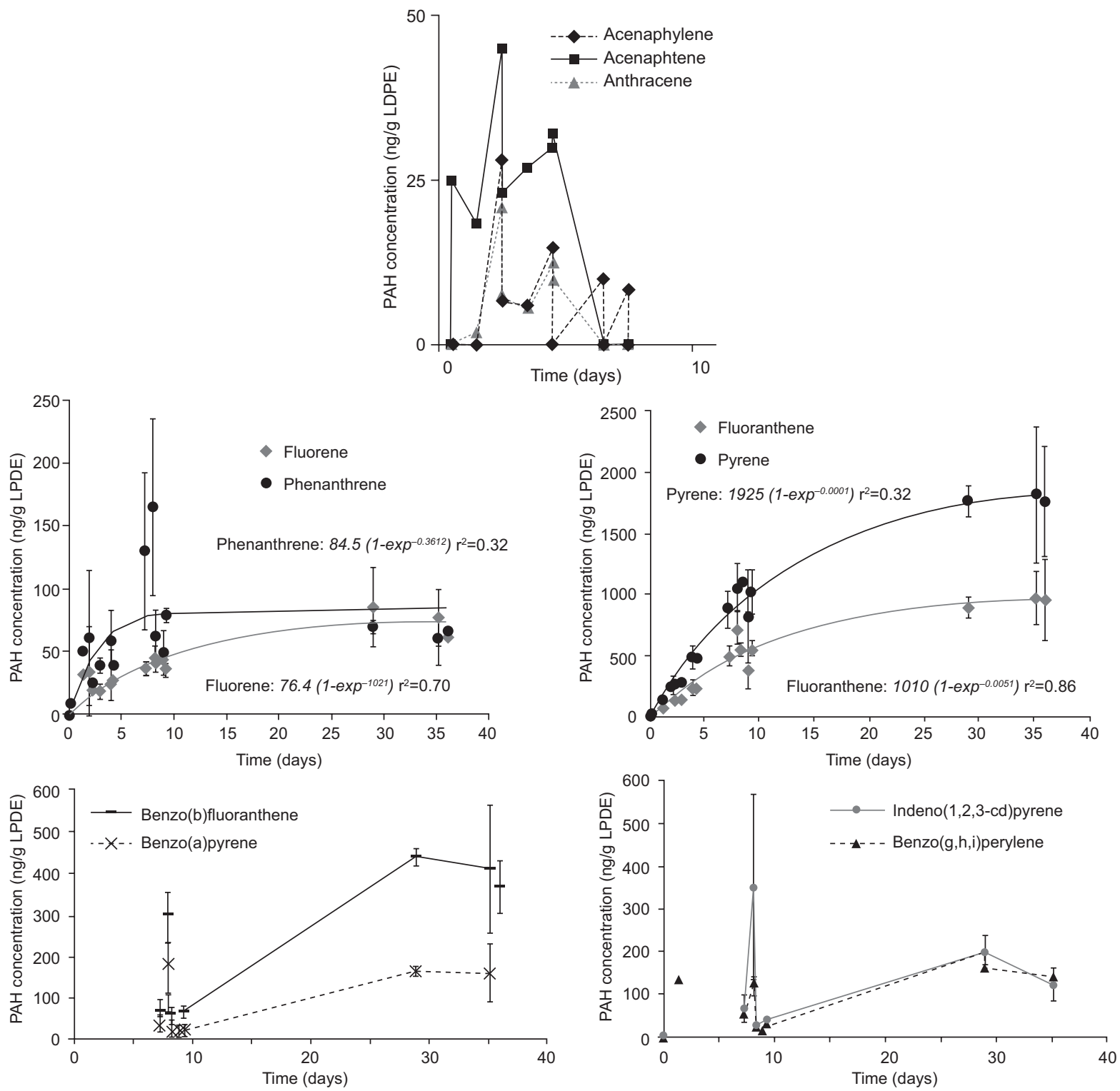

Fig. 3. (a) Concentration (ng/g) of acenaphthylene, acenaphthene and anthracene in low density polyethylene exposed (buried) in sediment during the 36-day experiment. Results from 10 days after the beginning of the experiment are zero, Not shown to enhance figure definition for early passive sampling. (b) Concentration (ng/g) of polycycic aromatic hydrocarbons (PAH) in LDPE exposed (buried) in sediment during the 36-day experiment. Average concentrations and standard deviation $(n=3)$. When possible, first-order kinetic curves were fitted to the experimental data (from Devault et al. 2010). 
One PAH for which accumulation in LDPE was detected but not quantified (and, thus not shown): dibenzo[a,h]anthracene.

Acenaphthylene, acenaphthene and anthracene profiles (Fig. 3a), show early accumulation for 2 to 4 days, and then decrease to an undetectable level seven days after. Even though the quantification limit $(25 \mathrm{ng} / \mathrm{g})$ restricts interpretation, figure 3a presents five quantifiable analyses in which all three PAH were detected seven days after the experiment began. However, their accumulation was detected but it was rarely quantified (less than $25 \%$ of the samples)

As previously indicated, fluoranthene and pyrene (Fig. 3b) first-order passive sampling kinetic profiles conformed the accumulation model expressed by Huckins et al (1993).

Benzo(a)anthracene, chrysene, benzo(b)fluoranthene, benzo(a)pyrene, indeno(1,2,3-c,d)pyrene, dibenzo(a,h)anthracene, benzo(g,h,i)perylene, phenanthrene and fluorene, presented (Fig. 3b) a low early accumulation, which showed a peak after a week and then showed a decrease followed by another increase of PAH in the LDPE of longer duration a month later. During the six last days of the experiment, a new decrease was initiated, more noticeable for benzo(b)fluoranthene, benzo(a)pyrene and indeno(1,2,3-c,d)pyrene. However, except for fluorine and phenanthrene which presented an accumulation profile close to first order kinetics, benzo(a)anthracene, chrysene, benzo(b)fluoranthene, benzo(a)pyrene, indeno(1,2,3-c,d)pyrene, dibenzo(a,h)anthracene and benzo(g,h,i)perylene accumulation were detected but rarely quantified (less than $25 \%$ of the samples)

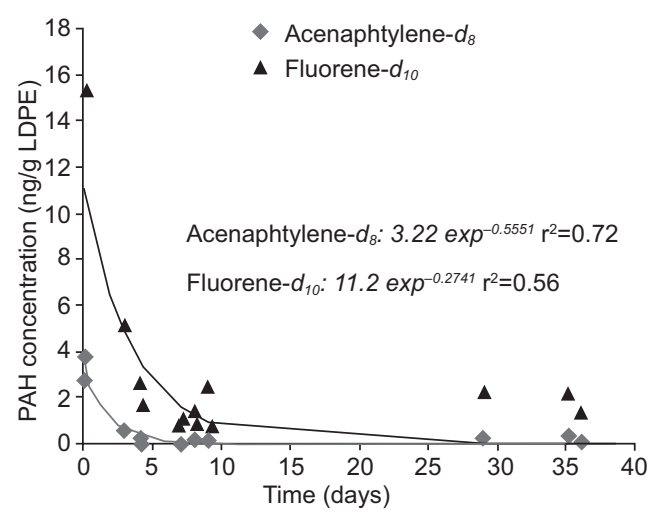

\section{Accumulation of PAH in tubed LDPE strips}

LDPE strips inserted into test tubes did not present any evidence of PAH uptake. Whatever the molecule, no accumulation profile was observed. Hence, accumulation did not occur.

\section{PRC desorption from LDPE}

Despite the great variability in PRC concentrations in buried LDPE, desorption followed first order kinetics with similar rates to those reported in the literature (Tomaszewski et al. 2008): the most hydrophilic PRC desorbed very rapidly (the acenaphthylene- $d_{8}$ concentration reached the detection limit after $24 \mathrm{~h}$ of exposure) whereas intermediary PRC (fluorene- $d_{10}$, fluoranthene- $d_{10}$ and anthracene- $d_{10}$ ) significantly desorbed after $36 \mathrm{~d}$ (Fig. 4). The least hydrophilic PRC did not desorb. For tubed LDPE, no significant desorption PRC occurred: initial PRC concentrations were quantified.

\section{DISCUSSION}

Buried LDPE were used to compare in-tube LDPE with classical sampling profiles. The interpretation of lone buried LDPE results contributed to a previous communication (Devault et al. 2010).

Contaminant recruitment mode is highlighted by the present experiment. LDPE inserted in a test tube were not subjected to pore water flow. Adsorption and desorption profiles ensure passive sampler inertia with environment. Inversely, buried strips presented adsorption and desorption corresponding to what reported by Álvarez et al. (2007) and Tomaszewski et al. (2008).

Fig. 4. Concentration of performance reference compounds in low density polyethylene exposed in sediment during the 36-day experiment. Average polycyclic aromatic hydrocarbons (PAH) concentration $(n=3)$ and first-order decreasing curves. 
Regarding tubed LDPE, introduction of LDPE was performed carefully to prevent organic matter dissolution (Jonker et al. 2001), which could lead to increase PAH concentration in pore water. This was confirmed since no accumulation was observed during the first days of exposure. Inversely, the early profile of acenaphthene, acenaphthylene and anthracene for buried LDPE could be attributed to insertion processes, more intrusive because of burial, even LDPE/sediment competition processes induced depletion after the initial period. In any case, introduction of LDPE into the test tube did not disturb the sorptive equilibrium of the sediment.

Fluoranthene and pyrene (respectively 5.12 and $\left.5.2 \log \mathrm{K}_{\mathrm{OW}}\right)$ passive sampling presented the most suitable profiles for interpretation. Accumulative fluctuations for most PAH, limited the interpretation because the kinetic regime is hard to characterise and the equilibrium regime was never reached. Whatever their $\mathrm{K}_{\mathrm{OW}}$ or aromaticity, molecules present an initial accumulation phase followed by a decrease. The decrease profiles in a polluted environment context are unexpected and should be explained.

\section{LDPE-PAH bound}

PAH adsorption on LDPE is disturbed after 5 to 10 $\mathrm{d}$, whatever the molecule considered. This desorption event was not observed on the PRC profile. However, decreasing profiles illustrate greater sampled PAH desorption from LDPE than concomitant adsorption. The type of adsorption binding or competition with other ligands could be involved.

Such phenomena seem to indicate a variation in the pattern of PAH adsorbed onto the LDPE: PAH act as if the binding of molecules adsorbed early were sufficiently strong, allowing reversibility not covered by the adsorption model, as shown by the PRC profiles. However, no studies with LDPE in the literature corroborate these findings.

Competition between the passive sampler and environmental ligands, especially organic matter such as humic acids (Durjava et al. 2007), could explain the sampling differences by less affinity PAH - LDPE sorption than PAH - organic matter sorption. Such early adsorption on LDPE followed by dominant desorption becomes stronger as the PAH is increasingly soluble: after 8 days, acenaphthene, acenaphthylene and anthracene became permanently undetectable (Fig. 3a).

The two interpretations could be combined to explain the predominant desorption pattern. With time, the succession of brief desorption-adsorption limits the organic chemical detection (Calvet et al. 2005) and favours strong bounds (Gaillardon et al. 1995, Gaillardon, 1996), leading to "ageing". This process could interfere in LDPE sorption (Hatzinger et al. 1995): LDPE short-term sorption involves PAH desorption which could favour long-term adsorption on sediment. Sediment accumulates contaminants owing to various generic characters: adsorption is partly explained by the affinity of PAH for: (i) organic structures $\left(\mathrm{K}_{\mathrm{OW}}, \mathrm{K}_{\mathrm{OC}}\right)$ especially aromatic ones (Karickhoff et al. 1979, Larson et al. 1984, Gao et al. 1997), (ii) convoluted structures like fine fractions $(<63 \mu \mathrm{m})$ where confinement opportunities abound, and (iii) organic carbon (Emsley 1980) "amorphous", with a flexible and macroporous structure such as humic acids, and a higher degree of aromaticity (Senesi 1992), "hard/condensed" such as carbonaceous microporous geosorbent (Ramade 1979, Perminova et al. 1999, Sun et al. 2008), which strongly binds hydrophobic organic contaminants (HOC) and reduces desorption. This is true to such an extent that Puglisi et al. (2007) assessed that around 30 to $62 \%$ of the original level of organic micropollutants remained in sediment several years after being trapped there. Sediment could thus be considered as a competitive agonist i.e. the contaminant affinity for the solid matrix and especially for the organic matter in sediment behaves like a passive sampler and, despite water, the most effective sampling by LPDE seems to result from its competition with the sediment matrix.

\section{Test tube LDPE vs. buried LDPE}

Comparison between test tube LDPE and buried LDPE presents an obvious difference. Sorption occurs in buried LDPE and not in test tube LDPE. The non occurrence of desorption, proven by the lack of PRC desorption in test tube LDPE, confirms the lack of PAH exchanges between LDPE and the medium. Although, the two month experiment is long enough to allow desorption of PAH as assessed by buried LDPE where desorption conventionally occurs (Devault et al. 2009) (3.1). Figure 2 highlights the elevated amounts of PAH in the sediment (in the range of 20 to $250 \mu \mathrm{g} / \mathrm{g}$ each) due to urban pollution. There were about $10 \mathrm{~g}$ of sediment in the test tube, so 0.2 to $2.5 \mu \mathrm{g}$ of each. While the most hydrophobic PAH can be logically considered to be desorbed too slowly to justify accumulation, this is not the case for the lightest PAH, and particularly not for acenaphthylene which remains at constant levels in the sediment (about 50 ng/g; Fig. 2). The detection limit in passive sampling by buried LDPE was about $50 \mathrm{ng} / \mathrm{g}_{\mathrm{LDPE}}$. However, neither sediment volume nor 
weight or amounts of PAH in the tube are significant for LDPE uptake.

Concerning metals, the extensively used diffusive gradient in thin-film (DGT) device is a closed sampler (Harper et al. 1998, 1999, 2000). The recruitment of metals occurs in a closed solid environment. DGT forces desorption of chemicals adsorbed on sediment particles in the millimeters around the operative resin. Traces of metals in the pore water are maintained in contact with the device - note though, that metal and organic pollutant binding are not comparable.

Circulation of water in test tube could be considered as substantially limited compared to buried strips, and confirmed by the desorption profile. The tubes were vertically pushed into the sediment (their number at each retrieval avoids spatial heterogeneity impact) and the pore water flow is considered to occur parallel to stream flow. Inversely, test tubes cannot be considered to fully restrain the pore water circulation in the boundary layer, thus explaining the very limited uptake of micropollutants by the LDPE. Sojitra et al. (1996) considered that fresh water, holding in the dissolved organic matter flocculation, is favourable to PAH transport. So, interpretations on fresh water LDPE sampling are fortified in marine sediment because the ionic strength increases due to salinity. Flocculation could occur, trapping adsorbed contaminants in macroporous circulation that become too narrow to allow flock circulation with pore water.

The desorption profile indicates inertia as does the adsorption profile. While it is highly probable that Rungis sediment has sufficient quantities of PAH to accumulate in LDPE, it is at least also probable that the sediment adsorption sites were not saturated. Thus, desorption should have occurred from the buried LDPE and the test tube LDPE during the two month experiment. However, (i) PRC concentration in boundary layer could be enough to stop the desorption process and (ii) post-desorption re-adsorption of PRC could reduce the apparent desorption profile. The results indicate that desorption, as adsorption, are ordered by pore water, its circulation provides freely dissolved accumulated chemicals and allows PRC desorption.

\section{CONCLUSION}

The present study ensures that LDPE cannot be used to estimate adsorbed molecules in sediment. We present empiric evidence that this passive sampler only samples the labile part of the pore water contaminants. The efficiency of LDPE seems to be restricted by competitive interactions with natural ligands, which abound in sediment. It would appear justifiable to conclude that there is no interference between the sediment ligands and such devices.

This study indirectly validates the practice of shaking in-lab sediment passive sampling: dissolved organic matter generated by sediment handling (Jonker et al. 2001) does interfere with hydrophobic organic contaminants freely dissolved in pore water.

\section{ACKNOWLEDGMENTS}

The authors wish to thank M. Combe and E. Uher for their support in sample analysis. Authors acknowledge P. Winterton for his help in the edition of the english version of the manuscript. This study was a part of the DIESE project, financially supported by the French National Water Agency.

\section{REFERENCES}

Allan I.J., Vrana B., Greenwood R., Mills G.A., Roig B. and Gónzalez C. (2005). Water quality monitoring: A toolbox in response to the EU's Water Framework Directive Requirements, water and wastewater. Intern. Environ. Technol. 15, 10-11.

Allan I.J., Booij K., Paschke A., Vrana B., Mills G.A. and Greenwood R. (2009). Field performance of seven passive sampling devices for monitoring of hydrophobic substances. Environ. Sci. Technol. 43, 5383-5390. DOI: $10.1021 / \mathrm{es} 900608 \mathrm{w}$

Allan, I.J., Ruus, A., Schaanning, M.T., Macrae, K.J. and Næs, K. (2012). Measuring nonpolar organic contaminant partitioning in three Norwegian sediments using polyethylene passive samplers. Sci. Tot. Environ. 423, 125-131. DOI: 10.1016/j.scitotenv.2012.02.027

Alvarez D.A., Huckins J.N., Petty J.D., Jones-Lepp T., Stuer-Lauridsen F., Getting D.T., Goddard J.P. and Gravell A. (2007). Tool for monitoring hydrophilic contaminants in water: polar organic chemical integrative sampler (POCIS). Chapter 8. Comp. Anal. Chem. 48, 171-197. DOI: 10.1016/s0166-526x(06)48008-9

Booij K., Sleiderink H.M. and Smedes F. (1998). Calibrating the uptake kinetics of semipermeable membrane devices using exposure standards. Environ. Toxicol. Chem. 17, 1236-1245. DOI: 10.1002/etc.5620170707

Booij K., Hoedemaker J.R. and Bakker J.F. (2003). Dissolved PCBs, PAH, and HCB in pore waters and overlying waters of contaminated harbour sediments. Environ. Sci. Technol. 37, 4213-4220.

DOI: $10.1021 / \mathrm{es} 034147 \mathrm{c}$ 
Calvet R., Barruiso E., Bedos C., Benoit P., Charnay M.-P. and Coquet Y. (2005). Les pesticides dans le sol - Conséquences agronomiques et environnementales. France Agricole Eds, Paris, France, 637 pp.

Charrasse, B., Tixier C., Hennebert P. and Doumenq P. (2014). Polyethylene passive samplers to determine sediment-pore water distribution coefficients of persistent organic pollutants in five heavily contaminated dredged sediments. Sci. Tot. Environ. 472, 1172-1178. DOI: 10.1016/j.scitotenv.2013.10.125

Cornelissen G., Wiberg K., Broman D.A.G., Arp H.P.H., Persson Y., Sundqvist K. and Jonsson P. (2008). Freely dissolved concentrations and sediment-water activity ratios of $\mathrm{PCDD} / \mathrm{Fs}$ and $\mathrm{PCBs}$ in the open Baltic sea. Environ. Sci. Technol. 42, 8733-8739.

DOI: $10.1021 / \mathrm{es} 8018379$

Coynel A., Schafer J., Hurtrez J.E., Dumas J., Etcheber H. and Blanc G. (2004). Sampling frequency and accuracy of SPM flux estimates in two contrasted drainage basins. Sci. Tot. Environ. 330, 233-247.

DOI: $10.1016 / j$. scitotenv.2004.04.003

Devault D.A., Combe M. and Gourlay-Francé C. (2010). ISTA 14 - In-situ accumulation of PAHs in low-density polyethylene passive samplers in sediment. Environ. Toxicol. 25, 527-532. DOI: 10.1002/tox.20598

Durjava M.K., ter Laak T.L., Hermens J.L.M. and Struijs J. (2007). Distribution of PAHs and PCBs to dissolved organic matter: High distribution coefficients with consequences for environmental fate modelling. Chemosphere 67, 990-997. DOI: 10.1016/j.chemosphere.2006.10.059

Ehlers G.A.C. and Loibner A.P. (2006). Linking organic pollutant (bio)availability with geosorbent properties and biomimetic methodology: A review of geosorbent characterisation and (bio)availability prediction. Environ. Poll. 141, 494-512.

DOI: 10.1016/j.envpol.2005.08.063

El Sebai T., Lagacherie B., Soulas G. and Martin-Laurent F. (2007). Spatial variability of isoproturon mineralizing activity within an agricultural field: Geostatistical analysis of simple physicochemical and microbiological soil parameters. Environ. Poll. 145, 680-690.

DOI: 10.1016/j.envpol.2006.05.034

Emsley J. (1980). Very strong hydrogen bonds. Chem. Soc. Rev. 9, 91-124. DOI: 10.1039/CS9800900091.

Ek K.H., Morrison G.M. and Rauch S. (2004). Environmental routes for platinum group elements to biological materials - A review. Sci. Total Environ. 334-335, 21-38. DOI: 10.1016/j.scitotenv.2004.04.027

Esteve-Turrillas F.A., Yusà V., Pastor A. and de la Guardia M. (2008). New perspectives in the use of semipermeable membrane devices as passive samplers. Talanta 74, 443-457. DOI: 10.1016/j.talanta.2007.06.019
Fernandez L.A., MacFarlane J.K., Tcacuic A.P. and Gschwend P.M. (2009). Measurement of freely dissolved PAH concentrations in sediment beds using passive sampling with low-density polyethylene strips. Environ. Sci. Technol. 43, 1430-1436.

DOI: $10.1021 / \mathrm{es} 802288 \mathrm{w}$

Gaillardon P. and Dur J.C. (1995) Influence of soil moisture on short-term adsorption of diuron and isoproturon by soil. Pest. Sci. 45, 297-303.

DOI: $10.1002 /$ ps.2780450402

Gaillardon P. (1996). Influence of soil moisture on longterm sorption of diuron and isoproturon by soil. Pesti. Sci. 47, 347-354. DOI: 10.1002/(SICI)10969063(199608)47:4<347::AID-PS419>3.0.CO;2-5

Gao J.P., Maguhn J., Spitzauer P. and Kettrup A. (1997). Distribution of pesticides in the sediment of the small Teufelsweiher pond (Southern Germany). Wat. Res. 31,2811-2819. DOI: 10.1016/S0043-1354(97)00123-1

Ghestem J.P. and Lachenal J. (2008). Incertitude sur l'échantillonnage et le prélèvement d'eaux: synthèse bibliographique. Bureau de Recherches Géologiques et Minières, Orléans, France, BRGM/RP-56885-FR, $58 \mathrm{pp}$.

Guimont S. (2005). Devenir des pesticides dans les sols en fonction de l'état d'humidité et du mode de circulation de l'eau dans le sol. Institut National Polytechnique de Lorraine. Nancy, France, 223 pp.

Harper M.P., Davison W. and Tych W. (2000). DIFS - A modelling and simulation tool for DGT induced trace metal remobilisation in sediments and soils. Environ. Model. Soft. 15, 55-66.

DOI: 10.1016/S1364-8152(99)00027-4

Harper M.P., Davison W. and Tych W. (1999). Estimation of pore water concentrations from DGT profiles: A modelling approach. Aqu. Geochem. 5, 337-355. DOI: 10.1023/A:1009620412373

Harper M.P., Davison W., Zhang H. and Tych W. (1998). Kinetics of metal exchange between solids and solutions in sediments and soils interpreted from DGT measured fluxes. Geochim. Cosmochim. Acta 62, 2757-2770.

DOI: $10.1016 / \mathrm{S} 0016-7037(98) 00186-0$

Hatzinger P.B. and Alexander M. (1995). Effect of aging of chemicals in soil on their biodegradability and extractability. Environ Sci. Technol. 29, 537-545.

DOI: $10.1021 / \mathrm{es} 00002 \mathrm{a} 033$

Hawthorne S.B., St Germain R.W. and Azzolina N.A. (2008). Laser-induced fluorescence coupled with solid-phase microextraction for in situ determination of PAHs in sediment pore water. Environ. Sci. Technol. 42, 8021-8026. DOI: 10.1021/es8011673

Hering D., Borja A., Carstensen J., Carvalho L., Elliott E., Feld C.K., Heiskanen A.-S., Johnson R.K., Moe J., 
Pont D., Solheim A.L., and van de Bund W. (2010). The European Water Framework Directive at the age of 10: a critical review of the achievements with recommendations for the future. Sci. Tot. Env. 40, 4007-4019. DOI: $10.1016 /$ j.scitotenv.2010.05.031

Huckins J.N., Tubergen M.W. and Manuweera G.K. (1990). Semipermeable membrane devices containing model lipid: A new approach to monitoring the bioavailability of lipophilic contaminants and estimating their bioconcentration potential. Chemosphere 20, 533-552. DOI: 10.1016/0045-6535(90)90110-F

Huckins J.N., Manuweera G.K., Petty J.D., Mackay D. and Lebo J.A. (1993). Lipid-containing semipermeable membrane devices for monitoring organic contaminants in water Environ. Sci. Technol. 27, 2489-2496. DOI: $10.1021 / \mathrm{es} 00048 \mathrm{a} 028$

Jonker M.T.O. and Koelmans A.A. (2001). Polyoxymethylene solid phase extraction as a partitioning method for hydrophobic organic chemicals in sediment and soot. Environ. Sci. Technol. 35, 3742-3748.

DOI: $10.1021 / \mathrm{es} 0100470$

Karickhoff S.W., Brown D.S. and Scott T.A. (1979). Sorption of hydrophobic pollutants on natural sediments. Wat. Res. 13, 241-248.

DOI: 10.1016/0043-1354(79)90201-X

Larson J.W. and McMahon T.B. (1984). Gas-phase bihalide and pseudobihalide ions. An ion cyclotron resonance determination of hydrogen bond energies in XHY- species (X, Y = F, Cl, Br, CN. Inorg. Chem. 23, 2029-2033. DOI: 10.1021/ic00182a010

Lorgeoux C. (2008). Développement d'échantillonneurs passifs pour les composes organiques hydrophobes. Mémoire du Conservatoire National des Arts et Métiers. Paris, France, 122 pp.

Perminova I.V., Grechishceva N.Y. and Petrosyan V.S. (1999). Relationship between structure and binding affinity of humic substance for polycyclic aromatic hydrocarbons: relevance of molecular descriptors. Environ. Sci. and Technol. 33, 3781-3787.

DOI: $10.1021 /$ es $990056 x$

Petty J.D., Orazio C.E., Huckins J.N., Gale R.W., Lebo J.A., Meadows J.C., Echols K.R. and Cranor W.L. (2000). Considerations involved with the use of semipermeable membrane devices for monitoring environmental contaminants. J. Chrom. A. 879, 83-95. DOI: 10.1016/S0021-9673(00)00315-0

Puglisi E., Murk A.J., Van Der Berg H.J. and Grotenhuis T. (2007). Extraction and bioanalysis of the ecotoxicologically relevant fraction of contaminants in sediments. Environ. Toxicol. Chem. 26, 2122-2128. DOI: $10.1897 / 06-581$ R.1

Ramade F. (1979). Ecotoxicologie, Masson, Paris, France, 228 pp. ISBN 978-2225455308.
Rantalainen A.-L., Ikonomou M.G. and Rogers I.H. (1998). Lipid-containing semipermeable membrane devices (SPMDs) as concentrators of toxic chemicals in the lower Fraser River, Vancouver, British Columbia. Chemosphere 37, 1119-1138. DOI: $10.1016 / \mathrm{S} 0045-6535(98) 00111-8$

Robertson A.M. and Lester J.N. (1994). Supercritical fluid extraction of s-triazines and phenylurea herbicides from sediment. Environ. Sci. Technol. 28, 346-351. DOI: $10.1021 / \mathrm{es} 00051 \mathrm{a} 023$

Sormunen A.J., Leppänen M.T. and Kukkonen J.V.K. (2008) Influence of sediment ingestion and exposure concentration on the bioavailable fraction of sedimentassociated tetrachlorobiphenyl in oligochaetes. Environ. Toxicol. Chem. 27, 854-863.

DOI: $10.1897 / 07-334.1$

Sormunen A.J., Tuikka A.I., Akkanen J., Leppänen M.T. and Kukkonen J.V.K. (2010). Predicting the bioavailability of sediment-associated spiked compounds by using the polyoxymethylene passive sampling and Tenax ${ }^{\circledR}$ extraction methods in sediments from three river basins in Europe. Arch. Environ. Contam. Toxicol. 59, 80-90.

DOI: $10.1007 / \mathrm{s} 00244-009-9453-1$

Senesi N. (1992). Metal-humic substances complexes in the environment. Molecular and mechanistic aspects by multiple spectroscopic approach. In: Biogeochemistry of trace metals. (D.C. Adriano, Ed.). CRC Press, Boca Raton, USA, Vol. 16, pp. 425-491.

Sojitra I., Valsaraj K.T., Reible D.D. and Thibodeaux L.J. (1996). Transport of hydrophobic organics by colloids through porous media 2. Commercial humic acid macromolecules and polyaromatic hydrocarbons, Coll. Surf. A: Physicochem. Eng. Asp. 110, 141-157. DOI: 10.1016/0927-7757(95)03433-1

Sun H., Wang C., Huo C. and Zhou Z. (2008). Semipermeable membrane device-assisted desorption of pyrene from soils and its relationship to bioavailability. Environ. Tox. Chem. 27, 103-111. DOI: $10.1897 / 07-120.1$

Tomaszewski J.E. and Luthy R.G. (2008). Field deployment of polyethylene devices to measure PCB concentrations in pore water of contaminated sediment. Environ. Sci. Technol. 42, 6086-6091. DOI: $10.1021 / \mathrm{es} 800582 \mathrm{a}$

Van Metre P.C., Mahler B.J. and Furlong E.T. (2000). Urban sprawl leaves its PAH signature. Environ. Sci. Technol. 34 4064-4070. DOI: 10.1021/es991007n

Weber W.J. Jr., McGinley P.M. and Katz L.E. (1991). Sorption phenomena in subsurface systems: Concepts, models and effects on contaminant fate and transport. Wat. Res. 25, 499-528.

DOI: 10.1016/0043-1354(91)90125-A 